\title{
EVALUATION OF TLC ANTIOXIDANT ACTIVITY AND PYTOCHEMICAL SCREENING OF LEAF EXTRACTS OF DISCHISTOCALYX HIRSUTUS C. B. CLARKE
}

\author{
Gloria Stéphanie Aurélia Amboyi ${ }^{1,2}$, Tsiba Gouollaly ${ }^{1}$, Timoléon Andzi-Barhé ${ }^{1}$, \\ Rodica Mihaela Dinica ${ }^{2}$, Mirela Praisler ${ }^{2 *}$ \\ ${ }^{1}$ Department of Chemistry, University Marien Ngouabi, , BP 69, Brazzaville Congo \\ ${ }^{2}$ Department of Chemistry, Physics and Environment, Faculty of Sciences and Environment, \\ "Dunarea de Jos" University of Galati, 47 Domneasca Street, Galati 800081, Romania, \\ e-mail: Mirela.Praisler@ugal.ro
}

\begin{abstract}
The study of phenolic compounds remains an area of the future because of the antiviral, antitumor, anti-inflammatory, anti-allergy, anti-cancer, healing, antiseptic and antioxidant properties they possess. The aim of our study was to evaluate the antioxidant activity and to evaluate the phytochemicals from the extracts (aqueous, hydroethanolic and ethanolic) of the leaves of Dischistocalyx hirsutus (Acanthaceae), a plant of the Congolese pharmacopeia. Our study showed the presence of several families, namely anthocyanins, flavonoids, tannins, cardiotonic heterosides and saponins. The presence of these different chemical families is more marked with the hydroethanolic extract. The TLC analysis by DPPH revealed the antioxidant potential of the extracts.
\end{abstract}

Keywords: Dischistocalyx hirsutus, antioxidant activity, phytochemicals, TLC, DPPH

\section{INTRODUCTION}

The inefficiency of certain modern drugs in the treatment of certain diseases, and the resistance that some micro-organisms have on certain currently available treatments, makes it essential to find new and more effective molecules to fight against certain infections, particularly those linked to blood and cardiovascular diseases [1 - 3].

Although much of the $20^{\text {th }}$ century was devoted to the development of synthetic molecules, the modern pharmaceutical industry today relies on the diversity of primary and secondary metabolites derived from the plant world, in order to find new molecules with unprecedented pharmacological properties. Thus, the search for new "lead compound" (active pharmacological agents) via plant screening has resulted in the discovery of a large number of useful drugs that are beginning to play a major role in the treatment of many diseases $[4,5]$.

For example, in 2004, the Ministry of Health and Population of the Republic of Congo, in its report on the "National Pharmaceutical Policy", strongly integrates in the health system the promotion of medicinal plants [6]. It is with the aim of contributing to this national policy that we propose to 
carry out the phytochemical study of the Dichistocalyx hirsutus leaves. This plant is traditionally used in Congo for the treatment of anemia and sickle cell disease.

Despite the progress made in medicine, many medical treatments remain insufficient in the face of plagues such as: anemia, sickle cell disease, malaria, cancer, Alzheimer, viral and bacterial infections. To remedy this situation, it is essential to look for new therapeutic substances. The investigation of plants represents an inestimable potential for the discovery of new substances. The aim of our work was to make a phytochemical screening of leaf extracts of $D$. hirsutus.

\section{EXPERIMENTAL}

\subsection{Plant material}

The species $D$. hirsutus is a medicinal plant of the African pharmacopoeia belonging to the family Acanthaceae. It is a species that grows in groups, with more or less creeping stems that have axillary buds necessary for reproduction by cuttings [7].

It is a herb whose height has been estimated between 60 and $90 \mathrm{~cm}$ [8]. Quite rare, it has been observed in Central Africa, mainly in the Congo, Gabon and Equatorial Guinea continental region [9]. D. hirsutus is used in northern Congo and southeastern Gabon in the treatment of anemia, sickle cell disease and arterial hypertension. The red decoction, characteristic of Anthocyanes, is swallowed with a little sugar to reduce the bitter character of the filtrate.

The leaves of D. hirsutus were harvested in the subprefecture of Kellé in the department of Cuvette-Ouest, in September 2017. The identification was made at the National Institute of Research in Natural Sciences (IRSEN) and a specimen was deposited at the National Herbarium and registered under number 7658 .

\subsection{Preparation of extracts}

The leaves of $D$. hirsutus used in this study were dried for 7 days at an ambient temperature of about $28^{\circ} \mathrm{C}$, protected from light. To keep track of mass loss during drying, weighing was done daily until the mass stabilized. The dry plant material was milled with a device of the type IKAWERKE GmbH-CO-KG, D-79219, Staufen, provided with a sieve of particle size $0.25 \mathrm{~mm}$.

$100 \mathrm{~g}$ of ground material were macerated for 48 hours in $500 \mathrm{ml}$ of different solvents: $100 \%$ ethanol, $50 \%$ (v / v) hydroethanol and $100 \%$ aqueous. After filtration of the filter, the filtrate is evaporated from the first rotary evaporator and empty at $-4{ }^{\circ} \mathrm{C}$., before being used for phytochemical screening, assay, characterization and radical activity.

\subsection{Demonstration by tube reactions}

Phytochemical screening is the ideal way to highlight the presence of chemical families present in a given plant. Two families were searched. These are total polyphenols and flavonoids. The principle is based on the addition of a reagent in an extract and then following the reactions that result: precipitation, color change, etc.

The detection tests of these chemical families were carried out according to the methods described by Sofowora, A. (1993) [8], as follows:

- Test for Tannins: about $0.5 \mathrm{~g}$ each portion was stirred with about $10 \mathrm{ml}$ of distilled water and then filtered. Few drops of $1 \%$ ferric chloride solution were added to $2 \mathrm{ml}$ of the filtrate. The occurrence of a blue-black, green or blue-green precipitate indicates the presence of tannins

- Test for terpenoids: a little of each portion was dissolved in ethanol. A quantity of $1 \mathrm{ml}$ of acetic anhydride was added, followed by the addition of conc. $\mathrm{H}_{2} \mathrm{SO}_{4}$. A change in color from pink to violet showed the presence of terpenoids. 
- Test for alkaloids: a small quantity of the each portion was stirred with $5 \mathrm{ml}$ of $1 \%$ aqueous $\mathrm{HCl}$ on water bath and then filtered. Of the filtrate, $1 \mathrm{ml}$ was taken individually into 2 test tubes. To the first portion, few drops of Dragendorff's reagent were added; the occurrence of orange-red precipitate was taken as positive. To the second $1 \mathrm{ml}$, Mayer's reagent was added; the appearance of buff-colored precipitate is an indication for the presence of alkaloids

- Test for Saponins: one gram of each portion was boiled with $5 \mathrm{ml}$ of distilled water and filtered. To the filtrate, about $3 \mathrm{ml}$ of distilled water was further added and shaken vigorously for about 5 minutes. Frothing which persisted on warming was taken as an evidence for the presence of saponins.

- Sodium hydroxide test for flavonoids: a small quantity of the each portion was dissolved in water and filtered; $2 \mathrm{ml}$ of the $10 \%$ aqueous sodium hydroxide was later added to it, in order to produce a yellow coloration. A change in color from yellow to colorless on addition of dilute hydrochloric acid was an indication for the presence of flavonoids.

\section{RESULTS AND DISCUSSION}

\subsection{Highlighting the major chemical families}

The phytochemical analysis, performed by using the three extracts of D. hirsutus leaves mentioned above, revealed the presence of several chemical families, which are presented in Table 1. We note the strong presence of flavonoids, tannins and traces of terpenoids (ladle) in all three extracts. On the other hand, saponins are present only in the aqueous extract. It should be emphasized that the alkaloids are absent in all three extracts. In view of the results obtained, we note a rather strong concentration of polyphenolic compounds.

Table 1. Phytochemical screening of the three leaf extracts of D. hirsutus

\begin{tabular}{|l|c|c|c|}
\hline Chemical family & Aqueous & $\begin{array}{c}\text { Hydro- } \\
\text { ethanolic }\end{array}$ & Ethanolic \\
\hline Alkaloids & - & - & - \\
\hline Flavonoids & +++ & +++ & +++ \\
\hline Tannins & +++ & +++ & +++ \\
\hline Saponins & ++ & - & - \\
\hline Terpenoids & $+/-$ & $+/-$ & $+/-$ \\
\hline
\end{tabular}

Legend: ++++ = very abundant; +++ = abundant; + = average;

Previous studies have shown that flavonoids, terpenoids, tannins, and saponins have important pharmacological properties, namely they are anti-inflammatory, diuretic, antiseptic and healing, antiviral, antitumor, anti-inflammatory, antiallergic anti-parasitic, surfactant, antioxidant and cardiotonic anticancer agents [13-15]. The presence of these different chemical families in D. hirsutus encourage its use in the primary health care. These results are in agreement with those obtained by Andzi-Barhé [17] on Dischistocalyx sp, a species of the same genus.

\subsection{Antioxidant activity by qualitative evaluation through Thin-Layer Chromatography} (TLC) 
The analysis of anti-free radical activity, performed with Thin Layer Chromatography (TLC) after revelation of the DDPH plate, indicates that the three extracts reduce in different ways. The chromatographic profiles show a yellow trail on the purple background, materializing the presence of a great anti-radical activity (see Fig. 1). This inhibition of free radicals varies according to the extracts and is sharper for the front-end reactions $(0.3$ and 0.5$)$ characterizing the flavonic compounds, which are known to be powerful anti-radical compounds. These chemical families were previously identified and assayed by Andzi-Barhe et al [17].

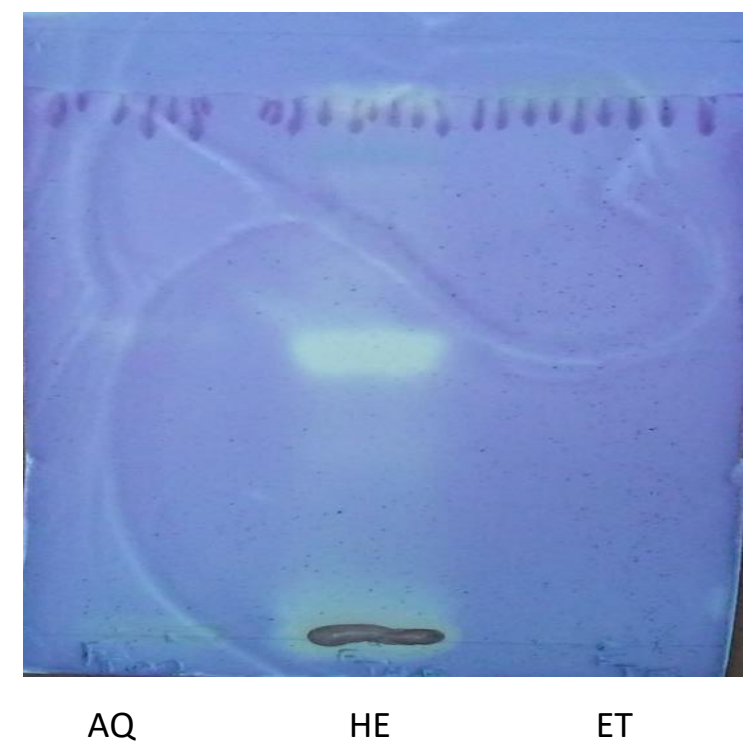

Fig. 1. Chromatographic profile of the hydroethanolic extract and fractions of $D$. hirsutus

\section{CONCLUSIONS}

The objective of our work was to make a phytochemical screening and to evaluate the antioxidant activity of $D$. hirsutus species of the family Acanhaceae, which is a plant of the Congolese flora that is traditionally used against several diseases, including anemia. The results indicate that: a) the leaves of this species are very rich in secondary metabolites; b) the hydroethanolic extractone is the richest in flavonoids and tannins; c) the hydroethanolic extract of the leaves has a greater antioxidant power than the other two extracts.

These chemical families are endowed with important pharmacological activities. Hence, this plant could be the object of several uses for therapeutic purposes due to its wealth of compounds with antioxidant effect.

\section{References}

1. Bernard J-P., Varet B., Clauvel J-P., Rain J-D., Sultan Y., The red blood cell: physiology and pathology. Abstract of Hematology, Masson, 2008.

2. Weatherall D .J., Clegg J. B., Inherited haemoglobin disoders: an increasing global health problem, Bulletin of the WHO., 79, 704, 2001.

3. Chan Agnes L. F., Leung Henry W. C., Wu Jia-Wen, Chien Tsair-Wei, Risk of hemorrhage associeted with co-prescriptions for Ginkgo biloba and antiplatelet or anticoagulant drugs, J. Altern. Complement. Med. 17(6), 513, 2011. 
4. Zohra M., Study of the antimicrobial and antioxidant power of essential oils and flavonoids of some plants of the region of Tlemcen, Memory of Magisterium, Abu Bakr Belkaïd Tlemcen University, Algeria, 2006.

5. Jansen P.C.M., Diospyros loureiriana G.Don, in: PROTA 3: Dyes and tannins/Colorants et tannins (Jansen, P.C.M., Cardon, D., Eds), PROTA, Pays Bas, 2005.

6. OMS, Who, Selected medicinal plants, vol. 1, Genève, 288, 1999.

7. https://fr.wikipedia.org/wiki/Acanthaceae

8. UNESCO, Pharmacopoeia and Traditional Medicine among the Pygmies of Gabon , 75, 2009.

9. Ministry of Scientific Research and Innovation, coll., Flora of Cameroon. Synopsis of endemic and rare vascular plant species in Cameroon: checklist for sustainable management and conservation of biodiversity, Yaoundé, 40, 62, 2013.

10. Békro Y.A., Janat A., Békro M., Boua B., Trabi, F. H., Ehouan E. E., Ethnobotanical study and phytochemical screening of Caesalpinia benthamiana (Baill.) Herend. and Zarucchi (Caesalpiniaceae), Sciences \& Nature, 4(2), 217, 2007.

11. Wagner H., Bladt S., Plant Drug Analysis, a Thin Layer Chromatography Atlas, 2nd Ed, Springer, NY, USA, 1996.

12. Bosabilis A., Tsekos I., Glandular scale development and essential oil secretion in Origanum dictamnus. L.,Planta 156, 496, 1982.

13. Svoboda K. P., Secretory structures of Aromatic and medicinal plant, Microscopix Publications, Powys, 2000.

14. Weast R. C. (Ed.), Handbook of chemistry and physics, 49th edition, The Chemical Rubber Co., F4, 1968.

15. Bourzix M., Influence of wine proanthocyanidins on health, Polyphénolic Phénoména, INRA, Paris, 1993.

16. Kim J., Proctective effect of Epillagocatechin-3-gallate on UVA and UVB-induced skin damage, Appl. Skin Physiol. 11, 19, 2001.

17. Andzi B. T., Obame E. L. C., Ondo J. P., Characterization of Anthocyanic compounds and evaluation of the radical scanvenging power of Glycine max L. Merr. Seed., International Journal of Current Chemical Sciences 3(5), 11, 2013.

18. Andzi-Barhé T., Massala K. K., Engonga L. C. O., Lebibi J., Phytochemical studies, total phenolic and flavonoids content and evaluation of antiradical activity of the extracts of the leaves from Dischistocalyx sp (Acanthacées), J. Pharmacogn. Phytochem., 3(6), 174, 2015. 